but it is important that the technologist, who would have to deal with human problems throughout his career, should also be able to bring a balanced outlook to bear on the questions of human relations or of administration with which he might be confronted. Prof. Garner maintained that properly taught engineering represents a complete discipline and a philosophy in the sense of the ability to see a particular field of knowledge in all its human relations. $\mathrm{He}$ protested strongly ogainst the tendency to compartmentalize knowledge and stressed the opportunities which are offered by borderland subjects like physical chemistry. With an educational training in the humanities, science, both pure and applied, can be taught so as to enable one to be clear, logical and objective, able to interest people, to assess evidence, form reasoned judgments and expldin them clearly to others. It is Prof. Garner's opinion that contact with industry in teaching applied science is essential and can with advantage be improved, especially where the training is being given in industry.

\section{Scientific and Technical Man-power in the United States}

The feature of No. 4 of News Report, issued by the National Academy of Sciences-National Research Council (Washington, D.C. ; July-August 1951) is an article by Dr. M. H. Trytten, director of the Office of Scientific Personnel, on the "Manpower Shortage in the United States". Analysing the intake available to maintain over a long period the projected military strength of 3.5 million men, Dr. Trytten points out that this figure has been achieved because of the existence of several groups-the pool of males without military service between the ages of eighteen and twenty six, personnel in military reserve status, and the career personnel. There are probably 750,000 career men now in the Armed Services; but to maintain a military strength of 3.5 million will require more than two years of service from all able-bodied youths, even 'without exemptions. With exemptions the average length of service of all youths not exempted must increase. Without exemptions the whole technology of the nation is in jeopardy. Meanwhile, the demand for technological personnel has mounted, and this summer more than twice as many scientific workers and engineers as were available could have been absorbed in research, production or teaching. It is also estimated that the output of scientific workers and engineers, even without the impact of the draft, is likely to decrease until at least 1955. In view of this situation the Director of Defence Mobilization has established a policy committee to make recommendations on all issues of policy affecting the handling of problems in utilizing scientific and technical personnel. The National Academy of Sciences appointed early in 1951 a com. mittee to examine the situation; and it is believed that the recommendations of this committee, which were adopted by the Academy in April and included the establishment of a National Scientific Personnel Board in the Office of Defense Mobilization to study intensively all such problems, will receive careful consideration when the problem of specialized manpower is discussed.

\section{The Scientific Outlook in 1851 and in 1951}

ThIs is the title of a Discourse delivered at the Royal Institution by Prof. $\mathrm{H}$. Dingle last March, and reproduced as an article in the August issue of the British Journal for the Philosophy of Science.
Prominence has been given at the recent Festival Exhibitions to the difference that science has made in practical affairs during the past hundred years. It is most fitting that there should be a permanent record of another aspect of scientific development, namely, the change in scientific outlook. In the first part of the article, Prof. Dingle emphasizes the basic assumption of the scientific men of 1851 that there was lying before them a world of material objects, moving about in space and time with, as Whewell maintains, a "substance, which stands beneath the apparent qualities and supports them". The reality of the substance was held to be its weight. Yet, as Prof. Dingle points out, it was the roundness and colour of Neptune, not its intrinsic property of weight, which was taken to be the guarantee of existence. The revolution that came in the twentieth century was simply the overthrow of that false notion of what science was and is; science itself has pursued the same undeviating course from Galileo through Newton and Einstein to our own time. The implications of the special theory of relativity are incompatible with any form of materialism. Prof. Dingle continues his argument to show the fallacy of the so-called philosophy of dialectical materialism. His treatment is both convincing and stimulating; the nineteenthcentury disputes between science and religion are shown in perspective, and of possible further conflict he believes that the highest wisdom lies in recognizing both the relations between experiences and the very different values of the things related : "The discarding of old prejudice and the cultivation of a new outlook are not matters that can be com. pleted in a moment". Prof. Dingle's article is a valuable contribution toward establishing this new outlook in place of dogmatic assertions of a hundred years ago.

\section{Errors in the Carbon-14 Method of Archæological Dating}

New lines of investigation are almost always welcomed with enthusiasm, more particularly when they involve disciplines in another subject than the one upon which they may throw light. It is a long time ago now since prehistorians were told all about their subject by human anatomists, and more recently the help of pollen analysis and the fluorine test has been readily accepted. Fortunately, the last two have been introduced to prehistorians by true scientific workers who have not failed to impress upon them the limitations and dangers of the new disciplines. Finally, there has appeared upon the scene the method of accurately dating prehistoric objects in years by analysing the percentage of the rare carbon-14 isotope present in material relative to the ordinary carbon-12. There is no doubt that this is a very valuable new method of study, and it has been taken up enthusiastically in the United States. Equally obviously, there are numberless factors, not perhaps all yet clearly understood, which may completely vitiate the results. A recent short article, only two pages in length, entitled "Radiocarbon Datability of Peat Marl, Caliche, and Archæological Materials", by H. H. Bartlett (Science, 114, No. 2951; July 20, 1951), describes just one such example. The author points out that when samples for study are taken from a site where alternating layers of marl and peat occur, the readings may be entirely erroneous owing to the presence of an unknown quantity of 'dead' carbon-12 derived from geologically ancient calcium carbonate; 